\title{
O MÉTODO ENQUANTO PRESSUPOSTO DE PESQUISA PARA O DIREITO: A CONTRIBUIÇÃO DE PIERRE BOURDIEU
}

\section{THE METHOD AS SEARCH FOR ASSUMPTION RIGHT: A CONTRIBUTION PIERRE BOURDIEU}

\author{
José Querino Tavares Neto
}

Professor Associado da Faculdade de Direito da Universidade Federal de Goiás, do Programa de Pós-Graduação em Direito da PUCPR e pós-doutor em Direito Constitucional pela Universidade de Coimbra com bolsa da Capes. Consultor das Faculdades Atenas. E-mail: jquerino@uol.com.br

Orides Mezzaroba

\begin{abstract}
Professor Associado em Dedicação Exclusiva nos Programas de Graduação e PósGraduação em Direito (Mestrado e Doutorado) da Universidade Federal de Santa Catarina. Possui Graduação em Direito pela Pontifícia Universidade Católica do Paraná (1986). Especialização em Filosofia da Educação pela Pontifícia Universidade Católica do Paraná

(1989). Mestrado em Direito pela Universidade Federal de Santa Catarina (1991).

Doutorado em Direito pela Universidade Federal de Santa Catarina (2000). Pós-

Doutorado junto à Universidade de Coimbra - Portugal (2008). Pesquisador de Produtividade do CNPq. Consultor da Coordenação de Aperfeiçoamento de Pessoal de

Nível Superior - Capes. Pesquisador com o projeto de pesquisa: "O endereço da transpersonalização dos atores políticos no processo de reconstrução do modelo de Estado de Direito no Brasil". E-mail: oridesmezza@gmail.com
\end{abstract}

Convidados

Doi: $10.5585 / \mathrm{rdb} . v 15 \mathrm{i} 6.455$

RESUMO: Seja por razões de desconhecimento seja pela ausência de referenciais teóricos, o Direito é um campo do saber que proporciona difíceis análises epistemológicas. As ciências jurídicas se entorpecem numa especificidade fraudulenta que encastela o ambiente acadêmico jurídico proporcionando restrição e pouca interdisciplinaridade. A maior dificuldade na análise reside na constatação de que o campo jurídico consubstancia-se num fenômeno pouco acessível, que não se deixa verificar na condição de objeto, conservando-se enrijecido em privilégios reflexos da condição decisória. Além disso, o Direito mostra-se possuidor de uma resistência perene a mudanças significativas e, mais grave, pouco preparado para enfrentar as novas demandas e categorias dos novos direitos, típicos da sociedade contemporânea. Nesse sentido, se propõe a partir de categorias de Pierre Bourdieu analisar-se a condição estrutural e estruturante do Direito como categoria dominante e, levantar algumas premissas que sejam sustentadas e discutidas para a importância da observância de um método e sua cientificidade no Direito.

Palavras-chave: Direito, Métodos, Metodologia, Pierre Bourdieu.

ABSTRACT: Either is for reasons of ignorance or the lack of theoretical frameworks, the law is a field of knowledge that provides difficult epistemological analysis. Legal science is dull in a fraudulent specificity that isolates the legal academic environment providing little restraint and interdisciplinarity. The main difficulty in analysis lies in the fact that the legal field is embodied 
in a little accessible phenomenon, which is not verify in the object condition, keeping hardened in privileges reflections of the operative condition. In addition to that, the law appears to be possessed of a resistance to significant changes and, even worse, is little prepared to face the new demands and categories of the new rights, typical of contemporary society. In this sense, it is proposed from categories of Pierre Bourdieu analyze the structural and structural condition of the law as the dominant category, and raise some assumptions that are supported and discussed to the importance of following a method and its scientific in Law.

Keywords: Right, Methods, Methodology, Pierre Bourdieu.

SUMÁRIO: Introdução; 1. Método e cientificidade; 2. Humildade acadêmica e cientificidade; 3. O método de Pierre Bourdieu; 4. O Direito como campo científico e modo de dominação; Conclusão; Referências.

SUMMARY: Introduction; 1 . Method and scientific; 2 . Humility academic and scientific; 3 . The method Pierre Bourdieu; 4. The Law as a scientific field and domination mode; Conclusion; References.

\section{INTRODUÇÃO}

A aplicação do método no âmbito do direito é recebida com certa resistência enquanto temática, de maneira que nessa área do conhecimento ainda permanece como um dos últimos redutos acadêmicos a aceitar a ideia de métodos para de análise e problematização.

Considera-se o método como um referencial ou quadro teórico conceitual de linha filosófica, religiosa, política, ideológica, sobre um autor, pesquisador e/ou estudioso, ou categoria que sirva para diferenciar ou comparar o modo de compreensão do sujeito sobre o objeto de estudo. Conforme Araújo (2003, p. 16) o método é "um caminho, um conjunto de regras e procedimentos comuns a várias ciências, que permitem obter explicações, descrições, sendo a compreensão mais adequada para as ciências humanas".

O método é um conjunto de procedimentos sistemáticos e racionais adotados para o desenvolvimento de uma pesquisa, um caminho ordenado para se chegar a um fim, ou seja, alcançar o objetivo definido, apresentando-se por sua vez enquanto elemento auxiliar na aquisição ou apreensão do conhecimento. O método coloca-se como marco teórico de fundamental importância na construção e definição da pesquisa, abrangendo tanto a convergência quanto a divergência, sendo então um pressuposto de análise e, por conseguinte, se impondo determinante e preponderantemente ao fenômeno da pesquisa, posto que a sua escolha não ocorra por necessidade descritiva, mas por imperativo analítico na qualidade de referencial teórico (matriz analítica).

Desta forma, considerando a escolha do método como imperativo analítico na definição da pesquisa, a contextualização do objeto será igualmente determinante, especialmente no cenário contemporâneo em que se vive um momento do conhecimento particularmente interessante, mas também cinzento, com o fim das metanarrativas (socialismo real versus capitalismo), verificadas pelo realinhamento dos blocos econômicos e políticos, o suposto fim da modernidade (o que não se evidencia porque existem espaços pré-modernos convivendo com pós-modernos) e o surgimento da pós-modernidade (todos dizem sobre ela, mas poucos sabem o que significa, dada a diversidade de interpretações a que a mesma se permite), e, mais recentemente, a primavera árabe.

A esse esmaecimento do próprio conflito histórico no âmbito global se soma as tentativas de se equacionar os problemas científicos, tecnológicos, econômicos e sociais que não 
encontram ressonância e correspondência efetivas no Fórum Econômico Mundial e no Fórum Social Mundial. Davos e Porto Alegre parecem órfãos, seja pela questão da representatividade, seja pelo objeto principal a que se destina.

No Brasil, o cenário se repete e percebe-se uma aparente ausência de sentido agudo quanto à noção militante, tão presente nos anos 70 e 80 do século XX em razão dos Movimentos Sociais históricos, populares e de trabalhadores. Tais movimentos começaram a se desvanecer nos anos 90 com o surgimento dos Novos Movimentos Sociais que, além de perder a noção de totalidade, também perderam foco pela chegada ao poder dos militantes dos movimentos dos trabalhadores no início do século XXI, além da consequente rotinização do poder com certa ausência da luta de classes.

O presente artigo se insere na discussão sobre a importância da utilização de métodos no processo de construção do conhecimento. Aqui será analisado o pensamento Pierre Bourdieu e sua possível contribuição para a realização de pesquisas na área do Direito. A questão que conduzirá o presente estudo será de responder se os fundamentos teóricos de Bourdieu possuem ou não aplicação em pesquisas que envolvam o mundo do Direito. O método a ser aplicado nesse estudo será o dedutivo.

\section{MÉTODO E CIENTIFICIDADE}

Uma das questões preocupantes observadas na atualidade, considerando o ambiente acadêmico em geral, é certo torpor hibernado, indiferença e apatia pela sensação de pouca efetividade docente e atratividade pelas carreiras acadêmicas, sobretudo, pela necessidade de método, sendo que, no âmbito jurídico, essa letargia é ainda mais premente do que em outras ciências humanas.

O Direito é, entre as ciências sociais, provavelmente, um dos segmentos menos influenciados pelo uso do método como instrumento de análise definidor. Há, é certo, um pequeno segmento imbuído dessa proposta, mas sua ação é ainda bastante restrita e certamente insuficiente. Isto provavelmente ocorre porque a consciência sobre a necessidade do método como elemento primordial da análise acadêmica jurídica ainda não atinge, em maioria, o ensino de graduação, sendo os bacharelados vocacionados ao exercício profissional.

Nesse sentido, algumas premissas devem ser levantadas para que sejam sustentadas e discutidas as principais características de um método e sua cientificidade no direito.

Em primeiro lugar, para que se inicie essa discussão, mostra-se recorrente a asseveração de que a ciência, apesar de sua precisão (MORIN, 2005), é apenas uma dentre outras formas de conhecimento, e não deve ser entendida como definitiva, isenta, muito menos absoluta (WEBER, 1993; RICHARDSON, 2010; FORTIN, 2007; MORIN, 2005; KUHN, 1978).

A proposição feita por Feyerabend $(2003$, p. 9) é bastante pertinente, pois indica a preocupação aqui tratada, visto que "a ciência deveria ser ensinada como uma concepção e não como o único caminho para a verdade e a realidade. Assim, o que se condiciona, fundamentalmente, é a consciência de que não há soluções gerais".

Esse modelo, longe de parecer superado, é imprescindível no âmbito da política, ciência, religião e cultura, como fator condicionante da pesquisa acadêmica, sobretudo pela insuficiência e perigosa perspectiva disciplinar e fragmentária (MORIN, 2005, p. 17). Para Feyerabend (2003, p. 319) "a ciência não é nem uma tradição isolada nem a melhor tradição que há, exceto para quem se acostumou com a sua presença, seus benefícios e suas desvantagens. Em uma democracia, deveria ser separada do Estado exatamente como as igrejas ora estão dele separadas".

Dessa forma, o método, enquanto instrumento da ciência, também não pode ser concebido como algo acabado, único e indiscutível. Nesse sentido afirma Andery (2007, p. 14) "o método não é único e nem permanece exatamente o mesmo, porque reflete as condições 
históricas concretas, as necessidades, a organização social para satisfazê-las, o nível de desenvolvimento técnico, as ideias, os conhecimentos já produzidos do momento histórico em que o conhecimento foi elaborado".

Deste modo, o que orienta a presente análise, é a perspectiva de que, enquanto tentativa de explicar a realidade, a ciência caracteriza-se como atividade metódica, e ao propor conhecer e explicar a realidade, a mesma busca atingir essa finalidade por meio de ações possíveis de serem reproduzidas. Mediante o que foi mencionado, o método científico é um conjunto de concepções sobre as regras de ação e procedimentos prescritos para se construir o conhecimento científico, inclusive o conhecimento jurídico enquanto uma forma de compreensão da realidade e, notadamente o Judiciário, como importante mediador na tentativa de resolução de conflitos.

Em segundo lugar, não é objetivo em uma análise de método e cientificidade, discutir a possibilidade de um método único e ideal para o direito ou qualquer outra forma de concepção da realidade, ainda que haja uma natural contaminação advinda das influências dos cursos de graduação e pós-graduação, fato este que em nenhuma hipótese indica uma suposta neutralidade acadêmica (WEBER, 1993).

Por uma série de razões, as ciências jurídicas e sociais somente podem ser apreendidas em suas concepções a partir de casos limites, como preconizava Weber (1993) em seu texto clássico Metodologia das Ciências Sociais. Para ele, a realidade é altamente trincada e difícil de ser apreendida, merecendo cuidado as perspectivas totalizantes, sendo a categoria do tipo ideal o principal instrumento metodológico para se estabelecer o significado cultural dos fenômenos, bem como para formular proposições empíricas sobre eles (SAINT-PIERRE, 1994, p. 67).

Em uma perspectiva supra histórica, Weber busca analisar a realidade a partir dos tipos ideais, encontrando nos tipos puros de dominação um mecanismo para que se tente taquigrafar a realidade histórica. A dominação racional estaria fundamentada "na crença da legitimidade das ordens estatuídas e do direito de mando daqueles que, em virtude dessas ordens, estão nomeados para exercer a dominação legal". A dominação tradicional estaria fundamentada "na crença cotidiana da santidade das tradições vigentes, desde sempre, e na legitimidade daqueles que, em virtude dessas tradições, representam a autoridade". Por fim, a dominação carismática seria aquela fundamentada na "veneração extra cotidiana, da santidade, do poder heroico, ou do caráter exemplar de uma pessoa e das ordens por esta revelada ou criada". (WEBER, 1991, p.141)

É importante salientar que os tipos de dominação estão sujeitos a combinações (mesclagem) entre si, o que dificulta sua análise objetiva, implicando necessariamente em fragmentações na incursão da realidade. Por conseguinte, numa visão estritamente weberiana, o objeto, longe de uma possível delimitação definitiva, carece de cuidado vigilante pela forma fluída e constante da transformação a que se sujeita. A sociologia compreensiva de Weber ensejou o estudo das ações sociais e das condutas orientadas para respostas determinadas, como pode ser percebido em sua obra prima, A ética protestante e o espírito do capitalismo, em que as ações devem ser entendidas a partir do substrato de sentido objetivado, ou seja, se faz necessário compreender o significado cultural dos fenômenos enquanto reflexo dos valores subjacentes das ações coletivas das seitas pietistas.

Em terceiro lugar, é importante que não se confunda método e metodologia. O método é a forma de compreensão e um pressuposto, enquanto que a metodologia é a ferramenta ou forma de registro acadêmico. De acordo com Araújo (2003), método é um conjunto de regras e procedimentos e dessa forma é o referencial ou quadro teórico conceitual orientado por uma linha filosófica, religiosa, política e ideológica de um autor, pesquisador e/ou estudioso, servindo para diferenciar ou comparar o modo de pensar das pessoas. Enquanto um conjunto de procedimentos sistemáticos e racionais adotados para o procedimento de uma pesquisa, é um caminho ordenado para se chegar a um fim, para alcançar o objetivo definido, ou ainda, como um elemento auxiliar na aquisição ou apreensão do conhecimento. 
Em quarto lugar, é preciso diferenciar-se o uso de um autor como referencial teórico, da adoção de um método de compreensão da realidade conforme proposto por um autor. Há autores respeitáveis cujo pensamento não fornece métodos de compreensão analítica; há outros cujas obras constituem-se em matrizes epistemológicas atreladas às suas formas de conceber e analisar a realidade. Assim têm-se a dialética marxista, o método tipo ideal weberiano, o estruturalismo de Lévi-Strauss, a concepção foucaultiana, bourdieusiana, dentre outros.

Deste modo, admite-se que o método é um pressuposto. Como as bases teóricas são de fundamental importância na construção e definição da pesquisa, percebe-se tanto a convergência quanto a divergência, sendo que o método se impõe de maneira preponderante ao fenômeno da pesquisa, uma vez que a escolha não se dá por necessidade descritiva (toda pesquisa deve ter), mas por imperativo analítico (existe de qualquer forma) na qualidade de referencial teórico (matriz analítica).

Para Popper (2007, p. 51), a epistemologia deve ser identificada com a teoria do método e, sendo este um pressuposto, não se pode afastar sua recorrente e necessária identificação com a epistemologia que, para além de puramente enunciados científicos, está fundada na escolha dos métodos como "decisões acerca da maneira de manipular enunciados científicos".

Assim, é na Epistemologia da Ciência que se concentra a problemática do método enquanto instrumento norteador do conhecimento, denominada de Filosofia da Ciência, na qual se têm os elementos fundantes da questão do método que,

[...] tem como objeto de reflexão e análise os métodos efetivamente empregados pelos cientistas em suas explicações visando distinguir seus procedimentos específicos e avaliar seu alcance, evidenciando as consequências filosóficas de sua adoção, bem como os princípios filosóficos que sustentam suas metodologias. O filósofo do método científico não tem o propósito de decidir qual é o método adequado e nem ensinar ou propor procedimentos metodológicos. Seu objetivo não é a própria pesquisa científica, mas as atitudes e os pressupostos filosóficos que estão por detrás da adoção do(s) método(s) científico(s). (ARAÚJO, 2003, p. 13, grifo nosso)

Em quinto lugar, é preciso uma postura vigilante, ético-crítica, em face dos riscos ideológicos a que se sujeita a temática do método. Dito de outra forma, não estaria ele mesmo (método) sujeito à ideologia? Deve-se ter sempre em mente a questão do método e da ideologia como a representação do mundo, tendo por finalidade motivar as pessoas, legitimar certas práticas e processos e mascarar uma parte dos pontos de vista e critérios utilizados (FOUREZ, 1995, p. 179). Não há neutralidade em face da ideologia, como na luta de classes indicada por Marx (1959, p. 129), para quem "o modo de produção da vida material é que condiciona o processo da vida social, política e espiritual. Não é a consciência dos homens que determina o seu ser, mas, inversamente, o seu ser social que determina a sua consciência".

De maneira pertinente, Chauí (1978) atualiza a concepção de ideologia ao afirmar que ela "não é apenas a representação imaginária do real para servir ao exercício da dominação em uma sociedade fundada na luta de classes, como não é apenas a inversão imaginária do processo histórico na qual as ideias ocupariam o lugar dos agentes históricos reais". Ou seja, "a ideologia é um corpo sistemático de representações e de normas que nos "ensinam" a conhecer e a agir".

Portanto, quando a ciência se apresenta como eterna, perene, objetiva e neutra (FOUREZ, 1995, p. 188), considerando para tanto a sua linguagem, cultura e dependência econômica do poder, sua tendência é a burocratização, o esvaziamento de sentido e a reificação de que nada mais é do que a coisificação dos seres humanos ou sua transformação em mercadoria (BOTTOMORE, 1988, p. 314).

Isso resulta na racionalização, que nada mais é que o resultado da especialização científica e da diferenciação técnica peculiar das sociedades ocidentais que proporciona uma 
maior eficácia e rendimento, como retratado por Weber na Ética Protestante e o Espírito do Capitalismo. Essa racionalização produz o processo de secularização e, portanto, a dessacralização da cultura e o respectivo desapego à tradição, reflexo este do processo produzido pela modernidade que proporciona o desencantamento do mundo, uma vez que a relação com o sagrado inverteu seu eixo central.

Até o século XVI o mundo era encantado, fruto direto da intervenção divina em todas as áreas da vida privada e pública - apesar da ausência de hegemonia plena da Igreja Medieval. Com a modernidade houve o desencantamento do mundo e, com isso, arrefeceu a magia e o sagrado, surgindo uma sociedade racional e orientada aos fins, o que resultou no capitalismo.

Expostas estas premissas, é prudente salientar que não somente a Ciência e o direito estão sujeitos aos riscos de subserviência. Esse pode ser o comportamento da arte, da música, do teatro, do cinema e da literatura. A exemplo de Flaubert (2006), cada um a seu modo corre o risco da sujeição ao determinismo economicista. Isso se evidencia nos grandes museus do mundo como exemplos de uma expressão mais elaborada e arguta do economicismo, como já indicava Benjamim (1996) sobre a reprodutividade técnica e massificadora da arte e, por conseguinte, sua subordinação à indústria cultural que mitiga a função emancipatória (ADORNO; HORKHEIMER, 1985).

\section{HUMILDADE ACADÊMICA E CIENTIFICIDADE}

Dentre todas as espécies, o homem é o único animal que relativiza a sua natureza e, por consequência, o meio em que se insere e até mesmo os mais remotos espaços que o fascina e o atrai, pois "ao mesmo tempo em que se constitui um ser natural, o homem diferencia-se da natureza" (MARX, 1984, p. 111). Isso se pode chamar de "o corpo inorgânico do homem" (ANDERY, et al., 2007, p. 9).

A interação homem/natureza é completamente diversa da que ocorre com os outros animais, uma vez que se estende para muito além da satisfação de suas necessidades vitais. Um simples exercício de observação sobre a vida humana indicaria o grau de excesso das coisas de que dispõem e, grande parte delas, desnecessárias, indicando total destemperança científica, racional e social.

Se pela observação da natureza encontram-se situações biologicamente determinadas, no ambiente acadêmico e social se faz necessário certa humildade para que se percebam os equívocos e as oportunidades reflexivas, ou então se estaria elaborando diagnósticos jurídicos numa perspectiva lombrosiana.

Socialmente falando, isso é muito problemático e até mesmo superado, mas em relação ao mundo animal, segundo Andery (2007, p. 9) "a sobrevivência da espécie se dá com base em sua adaptação ao meio. $\mathrm{O}$ animal limita-se à imediatividade das situações, atuando de forma a permitir a sobrevivência de si próprio e da sua prole; isso se repete, com mínimas alterações, em cada nova geração".

Portanto, o que se depreende é que, diferentemente das outras espécies que sobrevivem e se relacionam com o meio, quase de forma exclusiva pelo código genético (ANDERY, et al., 2007, p. 9), o homem, por intermédio da cultura, supera as próprias necessidades, cria novas e, sobretudo, reorganiza as próprias prioridades, gerando uma verdadeira inversão valorativa.

Assim, como o processo de reprodução humana é social e, portanto, quase não há chances de incidências isoladas de sobrevivência, no campo acadêmico existe a necessidade da multidisciplinaridade e, no caso em apreço, em relação ao método, é fundamental um "estado de humildade acadêmica", coisa nem sempre comum no campo científico jurídico (BOURDIEU, 1994). 
Por multidisciplinaridade, entende-se a proposta de Morin (2002; 2004) de transcendência à ideia disciplinar, que nem mesmo a interdisciplinaridade e a transdisciplinaridade conseguem superar, pois tendem à preservação. Para Morin (2002, p.115), a efetividade do conhecimento traduz-se pela consciência de que:

A multidisciplinaridade constitui uma associação de disciplinas, por conta de um projeto ou de um objeto que lhes sejam comuns; as disciplinas ora são convocadas como técnicos especializados para resolver tal ou qual problema; ora, ao contrário, estão em completa interação para conceber esse objeto e esse projeto, como no exemplo da hominização. No que concerne à transdisciplinaridade, trata-se frequentemente de esquemas cognitivos que podem atravessar as disciplinas, às vezes com tal virulência, que as deixam em transe. De fato, são os complexos de inter-multi-trans-disciplinaridade que realizaram e desempenharam um fecundo papel na história das ciências; é preciso conservar as noções chave que estão implicadas nisso, ou seja, cooperação; melhor, objeto comum; e, melhor ainda, projeto comum.

Isso se refere à consciência dos limites do processo do saber, normalmente condicionado a fatores disciplinares e à relevância do "outro" como conhecimento alternativo e auxiliar, já descritos por Morin como desafio da completude. Para Morin (2005, p. 176), uma vez que o problema da complexidade não é o da completude do conhecimento, mas sim a sua incompletude, confunde-se complexidade com completude.

Dessa forma, a humildade acadêmica e a efetividade implicam no reconhecimento dos limites do próprio saber, como indica Morin (2005, p.177):

De fato, a aspiração à complexidade tende para o conhecimento multidimensional. Ela não quer dar todas as informações sobre um fenômeno estudado, mas respeitar suas diversas dimensões: assim como acabei de dizer, não devemos esquecer que o homem é um ser biológico-sociocultural, e que os fenômenos sociais são, ao mesmo tempo, econômicos, culturais, psicológicos etc. Dito isto, ao aspirar a multidimensionalidade, o pensamento complexo comporta em seu interior um princípio de incompletude e de incerteza.

Tanto isso é verdade que se observa cada vez mais a composição de equipes multidisciplinares de pesquisas acadêmicas financiadas por órgãos de fomento, por causa da complexidade crescente dos objetos da pós-modernidade e da superação da perspectiva disciplinar, ainda muito mais nas ciências sociais aplicadas de natureza tão complexas como o direito, em que seus resultados demandam a determinação de implicações altamente intrincadas e consequências às vezes irreversíveis, inclusive em muitos casos com audiências públicas, a fim de orientar o processo decisório.

Por isso, "a possibilidade de testar e eventualmente refutar hipóteses e teorias científicas caracteriza melhor o procedimento do cientista do que a obtenção de verdade e certeza acerca dos fatos" (ANDERY, et al., 2007, p. 15). Novamente reporta-se aqui ao direito e à dificuldade de se estabelecer sua objetividade, mesmo que existindo critérios objetivos e subjetivos na sua aplicação em busca da verdade. Aliás, o que é a verdade no dizer sobre o direito pelo Judiciário? Como exaustivamente discutido, nem sempre há coincidência entre a verdade formal e a verdade real, o que se evidencia no tão usual brocardo jurídico: quod non est in actis non est in mundo, ou seja, o que não está nos autos não está no mundo.

Neste sentido, ao menos do ponto de vista do método, a verdade deveria ser a perfeita equação entre um fato ocorrido na realidade sensível e a ideia do que fazemos dela. Mas como isso seria possível se a realidade é altamente contaminada por fatores como a ideologia, a cultura, o social e, sobretudo, a economia? Nessa medida, o método auxilia 
no sentido de proporcionar uma melhor impressão da realidade (conceito), já que conscientiza da incompletude (MORIN, 2005) e, como indica Platão (1987), o conhecimento é o reflexo da assimilação metódica e disciplinar da forma analítica da realidade como fator derivado de um longo processo de libertação do mundo sensível.

\section{O MÉTODO DE PIERRE BOURDIEU}

Ao se considerar o método como um referencial teórico e forma de compreensão da realidade, logo um pressuposto de análise (ARAÚJO, 2003; WEBER, 1991; MARX, 1998), epistemologicamente, a teoria de Bourdieu, fundada em categorias marxistas, como a análise objetiva dos fatos sociais, e no método supra histórico weberiano, fornece elementos necessários para auxiliar na compreensão das possibilidades de construção de um Judiciário em suas mais diversas acepções e implicações.

A aplicação da teoria bourdieusiana enquanto método comprova-se também pelas incursões do autor em diferentes temáticas como a arte, cultura e educação (BOURDIEU, 2003), a profissão (BOURDIEU, 2002), as relações sociais de dominação, como a masculina (BOURDIEU, 1999), o poder em suas mais distintas perspectivas (BOURDIEU, 2000; 1998b), dentre outros temas. Constata-se, sem dúvida, na obra do autor a existência de uma epistemologia geral do mundo social, pois seus conceitos são de uma envergadura e sutileza somente vistas nos grandes clássicos do pensamento moderno, como Marx, Weber e Durkheim.

$\mathrm{Na}$ teoria bourdieusiana encontra-se uma profunda crítica ao saber enquanto fonte de validade e legitimidade do conhecimento, sobretudo, para que serve e, em que medida se aparelha e se traveste como instrumento da dominação em suas mais variadas dimensões, estratégias, engrenagens, estruturas, seja em uma dimensão macro, como é o caso da economia, seja numa micro dimensão, como os gestos, a linguagem, dentre outros aspectos.

Assim, pode-se afirmar que tudo serve à dominação enquanto processo de reprodução do poder, havendo ou não, por parte dos dominados, conhecimento e consciência acerca da arbitrariedade desse processo, conforme aponta Pinto (2000, p. 169),

[...] a principal contribuição de Bourdieu é propor interrogar o mundo social em geral e o campo político em particular à luz desse instrumento conceitual que é o modo de dominação, entendido como aquilo que permite a uma ordem social reproduzir-se no reconhecimento e do desconhecimento da arbitrariedade que a institui. Trata-se de compreender não apenas a "engrenagem" de um mecanismo complexo, com seus campos, seus capitais e suas estratégias, mas também as condições de possibilidade da submissão dos dominados à ordem social percebida e modo pré-reflexivo como ordem das coisas.

Nessa epistemologia, Bourdieu apresenta algumas categorias centrais a fim de nortear sua interpretação da realidade social, que são: a ortodoxia, que representa os dominantes e detentores do capital simbólico autorreferente, fundada na autoridade e altamente provida de capital específico da violência simbólica; a heterodoxia ou dominados, que dispõe de pouco capital estruturado e, consequentemente, se aproxima da heresia e da subversão; a doxa, como o universo de pressupostos dos agentes e as estratégias dos que lutam no interior do campo; o campo, estruturado pelas posições sociais derivadas de leis e regras próprias, ou seja, estrutura de relações objetivas derivadas do poder simbólico invisível e proveniente da cumplicidade entre os que o exercem e os que a ele se submetem; o habitus, como um conjunto de esquemas de classificação da realidade que se interiorizam pelos mais distintos processos estruturados e estruturantes, relacionados às práticas e às regularidades de conduta; a violência simbólica, que 
representa a dominação sutil nas mais diversas formas das relações sociais e de uma classe sobre a outra.

Para Bourdieu (1994, p. 145-146):

O campo de discussão que a ortodoxia e a heterodoxia desenham, através de suas lutas, se recorta sobre o fundo do campo da doxa, conjunto de pressupostos que os antagonistas admitem como sendo evidentes, aquém de qualquer discussão, porque constituem a condição tácita da discussão: a censura que a ortodoxia exerce - e que a heterodoxia denuncia - esconde uma censura ao mesmo tempo mais radical e invisível porque constitutiva do próprio funcionamento do campo, que se refere ao conjunto do que é admitido pelo simples fato de pertencer ao campo, o conjunto do que é colocado fora da discussão pelo fato de aceitar o que está em jogo na discussão, isto é, o consenso sobre os objetos da dissensão, os interesses comuns que estão na base dos conflitos de interesse, todo o não-discutido, o não-pensado, tacitamente mantidos fora dos limites da luta.

A violência simbólica, além da dominação de classe que se perpetua pela ausência de emancipação e alienação dos bens de produção da classe trabalhadora, num sentido estritamente marxista (BOURDIEU, 2000), também pode ser definida como violência "suave, insensível, invisível as suas próprias vítimas, que se exerce essencialmente pelas vias puramente simbólicas da comunicação e do conhecimento, ou, mais precisamente do desconhecimento, do reconhecimento ou, em última instância, do sentimento (BOURDIEU, 1999, p. 7-8).

Destaca-se que o processo de dominação somente tem eficácia se o mesmo for acompanhado de sistemas ideológicos promovidos por especialistas que lutam pelo monopólio da produção ideológica legítima, a fim de estabelecer um discurso dominante estruturado e estruturante (ortodoxia) para a domesticação dos dominados (BOURDIEU, 2000, p. 11), que nada mais seria do que a sedimentação do habitus na padronização do pensamento.

Neste diapasão, é importante esclarecer que, ao colocar em destaque a violência simbólica, Bourdieu jamais pretendeu minimizar os efeitos da violência física, mas sim, ao contrário disso, seu principal intuito foi salientar que qualquer tipo de violência subtrai suas verdadeiras motivações e reflexos no momento em que a mesma consegue ser legitimada e naturalizada. Isso se efetiva por meio da violência simbólica, portanto, "se institui por intermédio da adesão que o dominado não pode deixar de conceder ao dominante" (BOURDIEU, 1999, p. 47).

Esse é um conceito fundamental na literatura bourdieusiana em razão de que os poderes em geral e em especial, o Poder Judiciário serve-se da violência simbólica com grande eficiência, considerando-se que legitima seus atos por meio de princípios como o da legalidade/legitimidade do Estado de direito, elevados a Standards da justiça, mas, por outro lado, subtrai da sociedade - movimentos sociais, comunidades tradicionais, indígenas, quilombolas, redes socais - o direito/dever de promover a democracia participativa e ativa, como no caso da delicada temática da reforma agrária.

No que se refere ao campo jurídico, Bourdieu (2000, p. 229-230) encaminha sua proposta numa categorização da realidade a partir de tipos ideais determinados, dentre os quais o direito, sendo que, para ele:

A constituição do campo jurídico é um princípio de constituição da realidade (isto é, verdadeiro em relação a todo o campo). Entrar no jogo, conformar-se como o direito para resolver o conflito, é aceitar tacitamente a adopção de um modo de expressão e de discussão que implica a renúncia à violência física e às formas elementares da violência simbólica, como a injúria. É também, e, sobretudo, reconhecer as exigências específicas da construção jurídica do 
objecto: dado que os factos jurídicos são produto da construção jurídica (e não o inverso).

Neste contexto se faz importante destacar do pensamento de Bourdieu as definições de campo e habitus. Segundo o autor, o campo seria definido como "um estado da relação de força entre os agentes ou das instituições envolvidas na luta ou, se preferir, da distribuição do capital específico que, acumulado no decorrer das lutas anteriores, orienta as estratégias posteriores (BOURDIEU, 2003, p. 120). Por sua vez, o habitus, estaria relacionado com o "sistema de disposições adquiridas pela aprendizagem implícita ou explícita, que funciona como um sistema de esquemas geradores é gerador de estratégias que podem estar, objectivamente em conformidade com os interesses objectivos dos seus autores sem terem sido expressamente concebidos para esse fim". (BOURDIEU, 2003, p. 125)

O campo seria o espaço estruturado por posições em que os dominantes e dominados lutam pela obtenção e manutenção de postos específicos, e onde as posições dos agentes estão fixadas a priori; o habitus é o lugar do sujeito em seus mais diversos modos de ações condicionados e orientados a determinados fins.

Juntamente às noções de ortodoxia, hetorodoxia, campo, habitus, doxa e violência simbólica, existe ainda um conceito basilar em Bourdieu que é a homologia. Homologia na linguagem bourdieusiana se refere aos processos de estruturação objetiva comuns aos mais diversos campos sociais, ou seja, a possibilidade de observação pela equiparação entre suas formas de funcionamento sem a destruição de suas relativas autonomias no interior do campo social, tais como o campo do direito, do jornalismo, da Ciência Política, da biologia, matemática.

Para Bourdieu (2000) existe uma autonomia entre os campos (campo científico, religião, universidade, dentre outros), mas essa é uma autonomia relativa considerando-se que o fator econômico atravessa de forma imanente todos os campos. Deste modo, a homologia estrutural refere-se a uma noção que permeia toda a compreensão da realidade apreendida e, não apenas nos elementos latentes da sociedade, mas, sobretudo, nos patentes.

Assim sendo, considerando-se a sutileza estrutural do campo que estabelece a relação funcional entre os diferentes campos sociais, é possível, a partir das categorias essenciais (campo, habitus, violência simbólica), perscrutar que no interior desses campos, mesmo distintos e até contraditórios, sempre haverá associação a determinada posição social — iniciados, profanos, dominação, subordinação, violência simbólica, legitimação. Dessa forma, o método torna-se essencial, na medida em que sua função é a de apreender os conceitos existentes apenas no plano abstrato e sua transformação em categoria de análise, sendo que "a função propriamente ideológica do campo de produção ideológica realiza-se de uma maneira quase automática, na base da homologia de estrutura entre o campo de produção ideológica e o campo de luta de classes". Por sua vez,

A homologia entre os dois campos faz com que as lutas por aquilo que está especificamente em jogo no campo autônomo produzam automaticamente formas eufemizadas das lutas econômicas e políticas entre as classes: é na correspondência de estrutura e estrutura que se realiza a função propriamente ideológica do discurso dominante, intermediário estruturado e estruturante que tende a impor a apreensão da ordem estabelecida como natural (ortodoxia) por meio da imposição mascarada (logo, ignorada como tal) de sistemas de classificação e de estruturas mentais objectivamente ajustadas às estruturas sociais. (BOURDIEU, 2000, p. 13-14)

Mostra-se importante salientar que o conceito de violência simbólica está intimamente vinculado à ideia de homologia, funcionando por sua vez como elemento determinante, sustentador, equalizador e cimentar na teoria de Bourdieu. Esse conceito nada mais é do que a 
própria concepção da realidade e seu funcionamento, haja vista sua subsistência a todas as suas outras concepções e, mesmo prescindindo delas, nunca o contrário.

Bourdieu (2000, p. 210) estabelece uma teoria geral das relações sociais e como essa se aparelha e naturaliza sua forma de dominação, tendo o direito, especialmente, condição de espaço privilegiada para a produção e reprodução do poder.

Esse espaço de produção e reprodução do poder é categorizado por Bourdieu como campo. Ali acontecem as relações consequentes das estruturas referentes às posições sociais que funcionam com regras estabelecidas e derivadas de um poder simbólico invisível, mas facilmente perceptível nas estruturas sociais por ser proveniente da cumplicidade dos envolvidos nas relações sociais. Por essa razão, Bourdieu constitui uma teoria da formatação e funcionalidade da estrutura do campo, e de forma muito límpida, do campo científico.

É no campo científico onde se clarificam as mais diversas intenções e estratégias, visto ser “o universo 'puro' da mais 'pura' ciência é um campo social como outro qualquer, com suas relações de força e monopólios, suas lutas e estratégias, seus interesses e lucros, mas onde todas essas invariantes revestem formas específicas" (BOURDIEU, 1994, p. 121).

O campo científico, assim como qualquer outro espaço determinado ou indeterminado, é resultado de lutas anteriores em que acontece a luta concorrencial pela determinação do monopólio da autoridade científica concebida como capacidade técnica e poder social, denominada de competência científica. Nota-se que a capacidade técnica e o poder social são inseparáveis e, no caso do Poder Judiciário, derivam do domínio específico de um "corpus jurídico relativamente independente dos constrangimentos externos", facilmente identificáveis como lento, autoritário, elitista e pouco transparente, mas, sobretudo, naturalizado na estrutura do campo, pois, "Por seu lado, os juristas, pelo trabalho de racionalização e de formalização a que submetem o corpo de regras, representam a função de assimilação" (BOURDIEU, 2000, p. 210, 221).

Além das conexões já estabelecidas, Bourdieu (1994, p. 133) evidencia também uma íntima correlação entre o direito e o campo científico por causa de seus objetos similares que podem ser acumulados e, assim, transmitidos como capital simbólico, proporcionando visibilidade e reconhecimento. É a partir da acumulação do capital simbólico - como o reconhecimento acadêmico que, estruturalmente, se define pelo "estado das relações de força entre os protagonistas em luta, agentes ou instituições" - que se processa a distribuição do capital científico.

Deste modo, se no campo científico existe uma luta pelo monopólio do saber manifesto pelas mais diversas formas de reconhecimento dos pares (BOURDIEU, 1994, p. 126), no campo jurídico reproduz-se "um sistema fechado e autônomo, cujo desenvolvimento só pode ser compreendido segundo sua dinâmica interna" (BOURDIEU, 2000, p. 209).

Por essa pretensa dinâmica autorreferencial e regulatória do Direito e, por conseguinte, do Judiciário, evidencia-se que

A estrutura da distribuição do capital científico está na base das transformações do campo científico e se manifesta por intermédio das estratégias de conservação ou de subversão da estrutura que ela mesma produz. Por um lado, a posição que cada agente singular ocupa num dado momento na estrutura do campo científico é a resultante, objetivada nas instituições e incorporada nas disposições, do conjunto de estratégias anteriores desse agente e de seus concorrentes (elas próprias dependentes da estrutura do campo, pois resultam das propriedades estruturais da posição a partir da qual são engendradas). Por outro lado, as transformações da estrutura do campo são o produto de estratégias de conservação ou de subversão que têm seu princípio de orientação e eficácia nas propriedades da posição que ocupam aqueles que as produzem no interior da estrutura do campo. (BOURDIEU, 1994, p. 134) 
É por essa dinâmica que se observa em todos os campos das relações sociais o constante confronto entre ortodoxia e heterodoxia pelo controle e subversão da ordem estruturada que se sustenta e reproduz a partir das mais diversas estratégias de controle do tempo, espaço, saber/poder.

\section{O DIREITO COMO CAMPO CIENTÍFICO E MODO DE DOMINAÇÃO}

Em sua proposta de delimitação do Direito enquanto forma de dominação e seus modos de exercício, considerando que nomeadamente a maneira pelo qual se estrutura, reproduz e distribui os reflexos de seu poder simbólico, Bourdieu estabelece os elementos para um método de compreensão do Direito. O autor afirma que é necessário separar a "ideologia da independência do direito e do corpo judicial" sem que haja a prevalência de qualquer uma das visões, seja internalista ou externalista. Sendo antagônicas, uma ignora a outra. Para Bourdieu (2000, p. 211), “a existência de um universo social relativamente independente em relação às pressões externas, no interior do qual se produz e se exerce a autoridade jurídica, forma por excelência da violência simbólica legítima cujo monopólio pertence ao Estado, e que se pode combinar com o exercício da força física". Por sua vez, o que se verifica é que as práticas e os discursos jurídicos são, com efeito, produto do funcionamento de um campo cuja lógica específica está duplamente determinada: "por um lado, pelas relações de força específicas que lhe conferem a sua estrutura e que orientam as lutas de concorrência ou, mais precisamente, os conflitos de competência que nele têm lugar e, por outro lado, pela lógica interna das obras jurídicas que delimitam em cada momento o espaço dos possíveis e, deste modo, o universo das soluções propriamente jurídicas".

O Judiciário enquanto uma expressão institucional atua por excelência como forma de violência simbólica, em razão de que pode tanto combinar o uso da força física pelos instrumentos estatais quanto legitimá-la. Em suas soluções jurídicas e ao ocupar o monopólio da força tipificada pela lei, "o campo jurídico é o lugar de concorrência pelo monopólio do direito de dizer o direito, quer dizer, a boa distribuição (nomos) ou a boa ordem, na qual se defrontam agentes investidos de competência - ao mesmo tempo - social e técnica, isto é, na capacidade reconhecida de interpretar (de maneira mais ou menos livre e autorizada) um corpus de textos que consagram a visão legítima, justa, do mundo social". Para Bourdieu (2000, p. 212) será "esta condição que se pode dar as razões quer da autonomia relativa do direito, quer do efeito propriamente simbólico de desconhecimento, que resulta da ilusão da sua autonomia absoluta em relação às pressões externas".

Essa maneira de entender o Estado como fonte primaz do Direito e o Judiciário como único intérprete credenciado convive com recorrentes certames legitimatórios no âmbito acadêmico. Não obstante, apesar de poucas e isoladas tentativas, prevalece um universo restrito de legalidade que legitima atores autorizados a dizer o que é direito, e o condiciona a partir de uma linguagem altamente restrita e codificada para indicar um corpus legal que consagra a visão legítima e justa do mundo social e, portanto, o seu monopólio, pois, "o efeito de apriorização, que está inscrito na lógica do funcionamento do campo jurídico, revela-se como toda clareza na língua jurídica que, combinando elementos diretamente retirados da língua comum e elementos estranhos ao seu sistema, acusa todos os sinais de uma retórica da impessoalidade e da neutralidade". (BOURDIEU, 2000, p. 215- 216)

Para Bourdieu (2000, p. 220) "os juristas e outros teóricos do direito tendem a puxar no direito no sentido da teoria pura, quer dizer, ordenada em sistema autónomo e auto-suficiente, e expurgado, por uma reflexa firmada em considerações de coerência e de justiça, de todas as incertezas ou lacunas ligadas à sua gênese prática”. 
Por meio da linguagem oficial e oficiosa, extensiva a gestos, vestuário, relações sociais, formalidades e outros elementos, cristalizam-se os espaços privilegiados do poder jurídico e ocorre o mascaramento do caráter arbitrário das significações da dominação que interiorizam nas pessoas os elementos capazes de estruturar o ethos jurídico (MICELI, 1987, LIII).

Para Miceli, (1987, XLVIII) "o habitus constitui a matriz que dá conta da série de estruturações e reestruturações por que passam as diversas modalidades de experiências diacronicamente determinadas dos agentes". O que quer dizer que "o objeto da análise não se restringe apenas às práticas dos grupos, mas incide sobre os princípios de produção de que são o produto, vale dizer o habitus de classe e os princípios de produção de tal ethos, a saber, as condições materiais de existência". Assim, o desafio na abordagem do objeto de estudo está em "captar o processo pelo qual as estruturas produzem os habitus tendentes a reproduzi-las, isto é, produzem agentes dotados de um sistema de disposições conducentes a estratégias tendentes por sua vez a reproduzir o sistema das relações entre os grupos e/ou classes".

Com efeito, é por meio da interiorização de processos conducentes à reprodução de um sistema de relações sociais determinadas, que se pode verificar o que Bourdieu (2000, p. 224, 225) designa como a instituição do monopólio do espaço judicial que dicotomiza o jurídico/antijurídico e o legal/ilegal pelo corpus doutrinário. Também ali se procede a instituição do justiciável como um especialista e detentor de um ethos diferenciado, considerando que na prática "a instituição de um "espaço judicial" implica a imposição de uma fronteira entre os que estão preparados para entrar no jogo e os que, quando nele se acham lançados, permanecem dele excluídos, por não poderem operar a conversão de todo o espaço mental - e, em particular, de toda a postura linguística - que supõe a entrada neste espaço social."

O justiciavel funciona como tipo ideal (WEBER, 1993), a considerar sua finalidade como sendo a de oferecer aos dominados uma sensação de neutralidade da estrutura estruturante (jamais desinteressada), que seja capaz de ampliar os efeitos de sua atuação naturalizando a apropriação da linguagem, forma e estrutura do funcionamento judicante, que nada mais são do que estratégias de conservação no interior do campo. Para Bourdieu (2000, p. 227) o espaço judicial "funciona como lugar neutro, que opera uma verdadeira neutralização das coisas em jogo por meio da "des-realização" e da distanciação implicadas na transformação da defrontação directa dos interessados em diálogo entre mediadores". Por sua vez, o agente especializado permanece indiferente ao objeto que está diretamente sendo tratado (isto não quer dizer desinteressado) e preparado para "apreender a realidade escaldante do presente atendo-se a textos antigos e a precedentes confirmados - introduz, mesmo que sem querer nem saber, uma distância neutralizante a qual, no caso dos magistrados pelo menos, é uma espécie de imperativo da função que está inscrita no âmago dos habitus".

Esses espaços com regras e estruturas rígidas de distribuição do capital simbólico, funcionam como instrumento poderoso de sublimação do aspecto nefasto da subjugação inerente ao poder, legitimando-a, tornando-a ética e justificável pelo uso de meios inigualáveis de domesticação dos dominados. Por isso, Weber (1999, p. 197) salienta a relevância da organização como fundamento da validade da dominação, que no seu pensamento equivale à autoridade, e condiciona a significação da própria ordem jurídica.

Contudo, como legitimar o legal e tornar legítimo um espaço de funcionamento baseado na ambiguidade e no antagonismo como o jurídico? Para Bourdieu (2000) é exatamente esse poder arbitral, capaz de postular e conferir primazia prática à oposição entre verdadeiro e falso, que torna o veredito judicial eficaz e duradouro. Por isso, mesmo existindo oposição e resistência, observa-se um alto grau de autonomia do campo justiciável por ser

[...] o espaço social organizado no qual e pelo qual se opera a transmutação de um conflito directo entre partes directamente interessadas no debate juridicamente regulado entre profissionais que actuam por procuração e que têm 
de comum o conhecer e reconhecer da regra do jogo jurídico, quer dizer, as leis escritas e não escritas do campo - mesmo quando se trata daqueles é que é preciso conhecer para vencer a letra da lei (em Kafka, o advogado é tão inquietante como o juiz). (BOURDIEU, 2000, p. 229)

O campo jurídico e o Judiciário por excelência têm o primado da validade do direito (aspecto formal), ainda mais depois do ingresso no sistema constitucional brasileiro da súmula vinculante. Por isso, para Bourdieu (2000, p. 229) está se falando em pressuposto, pois a “constituição do campo jurídico é um princípio de constituição da realidade (isto é, verdadeiro em relação a todo o campo)".

Assim como no campo científico a tendência é a concentração nos problemas que os detentores do monopólio científico nomeiam mais importantes (BOURDIEU, 1994), inclusive de recursos dos órgãos de fomento, no campo jurídico, o pressuposto é a aceitação das regras e condições do campo pelo consagrado princípio do "estado de direito" e consequente renúncia à violência física, posto que "a constituição do campo jurídico é inseparável da instauração do monopólio dos profissionais sobre a produção e a comercialização dessa categoria particular de produtos que são os serviços jurídicos” (BOURDIEU, 2000, p. 233).

Portanto, é pelo Direito que se consagra a ordem estabelecida como visão do Estado, garantida por este e legitimada pelo Judiciário. No entanto, por meio dessa arguta impressão da legitimidade democrática, procede a uma regular subtração da sociedade do processo decisório, sobretudo sobre os seus próprios direitos, como no caso dos movimentos indígenas, quilombolas, comunidades tradicionais e outros, como nos indica Bourdieu (2000, p. 237) que, desta forma, "o direito é, sem dúvida, a forma por excelência do poder simbólico de nomeação que cria as coisas nomeadas e, em particular, os grupos; ele confere a estas realidades surgidas das suas operações de classificação toda a permanência, a das coisas, que uma instituição histórica é capaz de conferir a instituições históricas”. De forma mais enfática Bourdieu (2000, p. 238) é categórico ao afirmar que "o direito é a forma por excelência do discurso atuante, capaz, por sua própria força, de produzir efeitos. Não é demais dizer que ele faz o mundo social, mas com a condição de se não esquecer que ele é feito por este".

Como já salientado, o Direito, juntamente com os elementos do campo jurídico, incluindo suas profissões, dispõem da forma dos atos jurídicos e dos procedimentos como uma força a ser imitada, funcionando como fortes legitimadores do processo de dominação e perpetuação dos interesses comuns. Nesse sentido afirma Bourdieu (2000, p. 245), a atividade jurídica "exerce efeitos múltiplos: pela própria força da codificação, que subtrai as normas à contingência de uma ocasião particular, ao fixar uma decisão exemplar" que passa "a servir de modelo para as decisões ulteriores, e que autoriza e favorece ao mesmo tempo a lógica do precedente". Enfim, a atividade jurídica "constitui um dos fundamentos maiores da manutenção da ordem simbólica" na medida em que sistematiza e racionaliza "as decisões jurídicas e as regras invocadas para as fundamentar ou as justificar". Daí que se lhe confere "o selo da universalidade". A qual poderá "conduzir à universalização prática, quer dizer, à generalização nas práticas, de um modo de ação e de expressão até então próprio de uma região do espaço geográfico ou do espaço social".

Evidentemente que, além da forma, existem outras evidências de dominação no Direito. No entanto, apenas como exercício do exemplo, não é menos clarificador a própria composição do Direito na consagrada norma do artigo $4^{\circ}$ da Lei de Introdução do Direito Brasileiro (Lei n. 12.376/2010), que prima pela ideia de conjunto e exclusividade de fonte jurídica, já que as outras fontes são reconhecidas apenas por concessão. Sobre essa questão Bourdieu (2000, p. 246) assim se manifesta:

Compreende-se que, numa sociedade diferenciada, o efeito da universalização é um dos mecanismos - e, sem dúvida, dos mais poderosos - pelos quais se exerce 
a dominação simbólica ou, caso prefira, a imposição da legitimidade de uma ordem social. A norma jurídica, sob esse prisma, quando consagra em conjunto formalmente coerente de regras oficiais (e, por definição, sociais universais) os princípios práticos do estilo de vida simbolicamente dominante, tende a informar - realmente - as práticas do conjunto dos agentes, para além das diferenças de condição e de estilo de vida: o efeito de normalização, vem aumentar o efeito da autoridade social que a cultura legítima e os seus detentores já exercem para dar toda a sua eficácia prática à coerção jurídica.

Evidentemente, que qualquer análise do Direito, prima pela consciência do delicado liame saber/poder derivado, sobretudo, das novas formas de democratização dos processos sociais e seus reflexos, ainda que pequenos, no campo jurídico advindos da constitucionalização de direitos, democratização do Judiciário, e, num certo limite da ampliação de intérpretes legitimados em dizer o que é o Direito.

Esse fenômeno, ainda que tímido e ligeiramente insuficiente, funciona como mecanismo de reestruturação homóloga dos processos comuns aos mais diversos campos do conhecimento, oferecendo um instrumental hermenêutico do funcionamento do campo social em suas múltiplas representações.

\section{CONCLUSÃO}

A questão de um método como instrumento de análise do Direito não se resume na perspectiva bourdieusiana, muito menos em qualquer autor específico. No entanto, sua proposta de delimitação do Direito como forma de dominação e seus modos de exercício, considerando que nomeadamente a maneira pelo qual se estrutura, reproduz e distribui os reflexos de seu poder simbólico, estabelece os elementos para uma epistemologia, no mínimo, interessante, pra não dizermos, apropriada do Direito.

O Judiciário enquanto uma expressão institucional atua por excelência como forma de violência simbólica, em razão de que pode tanto combinar o uso da força física pelos instrumentos estatais quanto legitimá-la. Em suas soluções jurídicas e ao ocupar o monopólio da força tipificada pela lei,

Essa maneira de entender o Estado como fonte primaz do Direito e o Judiciário como único intérprete credenciado convive com recorrentes certames legitimatórios no âmbito acadêmico. Não obstante, apesar de poucas e isoladas tentativas, prevalece um universo restrito de legalidade que legitima atores autorizados a dizer o que é Direito, e o condiciona a partir de uma linguagem altamente restrita e codificada para indicar um corpus legal que consagra a visão legítima e justa do mundo social e, portanto, o seu monopólio.

Por meio da linguagem oficial e oficiosa, extensiva a gestos, vestuário, relações sociais, formalidades e outros elementos, cristalizam-se os espaços privilegiados do poder jurídico e ocorre o mascaramento do caráter arbitrário das significações da dominação que interiorizam nas pessoas os elementos capazes de estruturar o ethos jurídico e, finalmente, reproduzi-lo.

Esse universo de dominação que se processa por meio da interiorização de procedimentos conducentes à reprodução de um sistema de relações sociais designado por Bourdieu como a instituição do monopólio do espaço judicial, dicotomiza o jurídico/antijurídico e o legal/ilegal por um corpus doutrinário, procede a instituição do justiciável por especialista e detentores de um ethos diferenciado.

Essa análise, somente se torna possível, a partir de propostas metodológicas de análise do Direito como a indicada por Bourdieu. 


\section{REFERÊNCIAS}

ADORNO Theodor W. \& HORKHEIMER Max. Dialética do esclarecimento. Rio de Janeiro: Zahar., 1985.

ANDERY, Maria Amélia. et al. Para compreender a ciência: uma perspectiva histórica. Rio de Janeiro: Garamond, 2007.

ANDERSON, Perry. As origens da pós-modernidade. Lisboa: Edições 70, 2005.

ARAÚJO, Inês Lacerda. Introdução à filosofia da ciência. 3. ed. Curitiba: UFPR, 2010.

BOURDIEU, Pierre. O senso prático.. Petrópolis: Vozes, 2009. Questões de sociologia. Lisboa: Fim de Século, 2003. . O poder simbólico. Rio de Janeiro: Bertrand Brasil, 2000. . A dominação masculina. Rio de Janeiro: Bertrand Brasil, 1999. - O que falar quer dizer. Lisboa: Difel 82., 1998. . Economia das trocas lingüísticas.. 2. ed. São Paulo: USP, 1998b. - A Economia das Trocas Simbólicas. São Paulo: Perspectiva, 1987. . O campo científico. In: ORTIZ, Renato (Org.) Pierre Bourdieu. Sociologia. São Paulo: Editora Ática, 1994.

BOTTOMORE, Tom (Org.). Dicionário do pensamento marxista. Rio de Janeiro: Jorge Zahar Editor Ltda., 1988.

CHAUÍ, Marilena. O discurso competente. Revista da Associação Psiquiátrica da Bahia, vol. 2, n. 1., 1978.

FLAUBERT, Gustave. A educação sentimental. São Paulo: Martin Claret, 2006.

FEYERABEND, Paul. Contra o método. São Paulo: Editora da UNESP, 2003.

FORTIN, Robin. Compreender a complexidade: introdução ao método de Edgar Morin.. Lisboa: Piaget, 2007.

FOUREZ, Gerard. A construção das ciências: introdução à filosofia e à ética das ciências. São Paulo: UNESP, 1995.

GATTI, Bernardete A. et al. A atratividade da carreira docente. A condição pós-moderna. 3. ed. Lisboa: Gradiva, 2003.

KUHN, Thomas. A estrutura das revoluções científicas. São Paulo: Perspectiva, 1978.

MARX, Karl. O capital: crítica da economia política. São Paulo: Nova Cultural, 1988. . Prefácio à "Contribuição à Crítica da Economia Política”. Londres: [s.n], 1859. 
MICELI, Sérgio. Introdução: a força do sentido. In. BOURDIEU, Pierre. A Economia das Trocas Simbólicas. São Paulo: Perspectiva, 1987.

MORIN, Edgar. Ciência com consciência. 8. ed., Rio de Janeiro: Bertrand, 2005.

. Saberes locais e globais: o olhar transdisciplinar. Rio de Janeiro: Garamond, 2004.

A cabeça bem-feita: repensar a reforma, reformar o pensamento. 7. ed. Rio de Janeiro: Bertrand Brasil, 2002.

PINTO, Louis. Pierre Bourdieu e a teoria do mundo social. Rio de Janeiro: Editora FGV, 2000.

PLATÃO. Os pensadores. 4. ed. São Paulo: Editora Nova Cultural, 1987.

POPPER, Karl Raimund. A lógica da pesquisa científica. 13. ed. São Paulo: Cultrix, 2007.

RICHARDSON, Roberto Jarry. Pesquisa social: métodos e técnicas. 3. ed. São Paulo: Atlas, 2010.

SAINT PIERRE, H. L. Max Weber: entre a paixão e a razão. Campinas: UNICAMP, 1994.

WEBER. Max. Economia e Sociedade. Brasília: Editora da Universidade de Brasília. 1999. . Metodologia das Ciências Sociais. 2. ed. São Paulo: Cortez; Campinas: EdCamp, 1993. 